\title{
Lembranças de escola na formação inicial de professores/as
}

\author{
The role of school memories in the \\ first stages of teacher training
}

\author{
Renata C. O . Barrichelo CUNHA*
}

\begin{abstract}
Resumo: Quais as lembranças da escola que permeiam a formação inicial de professores/as? Qual o sentido da escola básica, o significado das experiências vividas como aluno/a, o vínculo construído com o conhecimento pelos professores/as em formação? Investigar as memórias dos/as alunos/as do curso de formação inicial de professores/as para conhecer suas experiências e lembranças significativas da escola foi o trabalho exercitado pela presente professora-pesquisadora, docente de um curso Normal Superior de uma faculdade privada do interior do Estado de São Paulo. As análises dos registros escritos elaborados pelos/as professores/as em formação apontaram que a escola tem sido vivida principalmente como espaço de encontro com os amigos, onde as confraternizações, festas, formaturas, amizades e brincadeiras e também o carinho de alguns professores têm maior importância do que as experiências com o conhecimento, com o estudo e a aprendizagem. Essas conclusões provocam algumas discussões e convidam os profissionais envolvidos com a formação de professores a uma reflexão importante, uma vez que se coloca para os cursos iniciais o enorme desafio de promover uma relação prazerosa com o conhecimento, com a leitura, com a escrita, com a necessidade de se encantar com o que não se sabe. Esse diálogo se propõe a discutir os depoimentos e as memórias dos/as professores/as em formação, as contribuições da escola básica, a questão da valorização do conhecimento no espaço escolar e o compromisso ético implicado no processo de aprender e ensinar.
\end{abstract}

Palavras-chave: formação inicial de professores, currículo, professor-pesquisador

Abstract: What are the school memories that influence the first stages of teacher training? What significance does elementary school have? What meaning do experiences as former students have? What meaning does the bond built on knowledge between peers have?

\footnotetext{
* Mestranda no GEPEC - Grupo de Estudos e Pesquisas em Educação Continuada - na Faculdade de Educação da UNICAMP. Email: rb_cunha@hotmail.com
}

Olhar de professor, Ponta Grossa, 8(1): 23-38, 2005. 
The aim of this work was to analyze the memories of students attending the first stages in teacher training and to learn about their experiences and more significant memories. This study was carried out by teacher and researcher, at a private university in the interior of the state of São Paulo. Analysis of the records written by teacher-students showed that school was mainly seen as a place for meeting friends and where events such as parties, graduations, friendship, games and teachers' displays of affection are a lot more important than experiences with acquiring knowledge, studies and learning. These conclusions generate important discussions and invite the professionals involved with the teachers' initial education to reflect on this fact, since these courses face the challenge of promoting a pleasant relationship with knowledge, reading writing and encouraging a fascination for the unknown. This work proposes to discuss the testimonies and memories of teacher-students, the contributions of elementary and secondary school, the importance given to learning in a school environment and the ethical commitment implied in a learning and teaching process.

Key words: teachers' initial education, curriculum, teacher-researcher

Quando assumi duas disciplinas - Fundamentos Psicopedagógicos da Educação e Literatura Infantil para as Séries Iniciais - de uma turma de $1^{\circ}$. ano do Curso Normal Superior numa faculdade privada de uma cidade do interior do Estado de São Paulo, em 2004, minha preocupação inicial foi conhecer o grupo para começar a ajustar meu plano de trabalho às necessidades e características da turma.

Minha expectativa era encontrar professoras em exercício que tivessem cursado o Magistério e que agora estivessem buscando a qualificação em nível superior. Essa não era a realidade do grupo. No primeiro encontro, descobri que eram alunas que não atuavam na Educação, recém-saídas do Ensino Médio, que atuavam basicamente no comércio. Algumas alunas, na faixa dos 28-40 anos, também em atividade no comércio ou no lar, recorriam ao curso para garantir a oportunidade de cursar uma faculdade. Nenhuma delas era professora.

Estranhei. Constatei, em seguida, que a realidade da formação inicial no nível superior e o perfil dos/as alunos/as dos Cursos Normais Superiores (e até mesmo da Pedagogia) modificaram-se. Com a extinção do curso Magistério em nível médio, o início da formação se dá agora nos Institutos Superiores de Educação ou na Universidade. Dessa forma, não temos mais, no Curso Normal ou na Pedagogia, alunos/as que fizeram estágios ou já ingressaram na docência, como era comum. Não encontramos alunos/as com experiências de professores/as, com dúvidas e conflitos inerentes à teoria-prática, com questões e problemas da sala de aula. 
Essa constatação foi importante para a consideração das minhas aulas: eu não tinha um grupo para discutir e refletir sobre a própria prática docente. De que forma eu iria tratar do programa idealizado, se elas não estavam em atividade, não poderiam aplicar, experimentar, inventar jeitos e maneiras de se tornarem professoras? Como tornar os conteúdos atraentes e significativos para um exercício profissional a ser ainda construído? O estágio supervisionado estava previsto para o $2^{\circ}$ e $3^{\circ}$ ano do curso e naquele momento não poderia ser articulado às aulas.

Por que essa preocupação me ocupava? Porque eu estava alinhada com a idéia de valorizar a formação pautada na reflexão sobre a prática e com a alteração da perspectiva da formação, substituindo um saber descontextualizado por um fazer reflexivo (PORTO, 2000), que permitisse trazer à tona diferentes leituras das realidades dos/as alunos/as no confronto com hipóteses explicativas e situações problemáticas (SANTOS, 2002).

Sacristán e Pérez Gómez (1998) são autores que ressaltam justamente que a prática não pode ser deduzida diretamente de conhecimentos científicos descontextualizados das ações em situações reais. Modelos, padrões, generalizações e esquemas não atendem às singularidades dos eventos da sala de aula.

Embora reconheça, com Pimenta (2002), que o saber docente não é for- mado apenas de prática, mas que é nutrido pelas teorias da educação e que a mera reflexão sobre o trabalho da sala de aula é insuficiente para a compreensão teórica dos elementos que condicionam a prática, entendo que sem a vivência da docência simultânea aos estudos das teorias, a possibilidade de compreensão dos contextos históricos, sociais, culturais, organizacionais da educação fica comprometida.

Em síntese, eu tinha um grupo com a própria experiência de alunas, uma representação de escola, de ensino e aprendizagem que eu precisava conhecer para poder problematizar. Falar da escola e pensar o desenvolvimento dos alunos, a organização do currículo e a importância da Literatura Infantil - conteúdo de uma das minhas disciplinas - era um projeto que eu tinha que associar e articular com o repertório que o grupo tinha vivenciado na escola enquanto alunas.

É importante reconhecer, também, que a formação do/a professor/a está relacionada ao imaginário social que a sociedade constrói historicamente (Cunha, 2004a), ou seja, os/as alunos/ as dos cursos de formação de professores, de forma clara ou não, já possuem marcos conceituais da profissão.

Em outro trabalho, Cunha (1997, p. 81) destaca que

As pesquisas sobre formação de professores (CUNHA, 1988; PIMENTEL, 1993; ANDRÉ, 1993) mostram que a principal influência no comportamento do profes- 
sor é sua própria história como aluno e que, para além das teorias pedagógicas que ele aprende, o que marca seu comportamento são as práticas de seus antigos professores.

Considerando que a experiência como alunas era constitutiva para referenciar a representação de professor/a, aluno/a, aprendizagem, estudo, algumas dúvidas colocavam-se: o que será que as alunas viveram na escola e que lhes trouxe alegria e satisfação? Quais suas lembranças mais significativas? Gostavam de estudar e aprender na escola básica?

Para investigar suas lembranças, adotei o pretexto de uma leitura. Fiz a leitura do livro "Guilherme Augusto Araújo Fernandes”, de Foz (1995), como estratégia para introduzir o tema das memórias, no nosso caso, as memórias escolares.

O livro narra a história de um garoto que mora ao lado de um asilo e que depois de ouvir uma conversa entre seus pais e a observação da mãe sobre uma senhora do asilo "Coitada da dona Antonia, está perdendo a memória..." - decide pesquisar o que era uma memória. Com delicadeza, interroga vários idosos e colhe explicações, como: memória é algo quente, memória é algo antigo, é algo que faz rir, que faz chorar, que a gente se lembra, que vale ouro...

Para ajudar dona Antonia a recuperar sua memória, Guilherme monta uma caixa com objetos com "características" associadas a elementos quentes, antigos, que faziam rir e chorar....... Dona Antonia se encanta com a coleção e associa aqueles objetos do garoto a suas lembranças de criança. Reencontra sua memória de infância.

\section{O DESAFIO DE REMEMORAR AS EXPERIÊNCIASDA ESCOLA}

Depois da leitura, propus às alunas o desafio de rememorar experiências e situações do universo vivido na escola. Cada uma tinha que escrever uma memória "quente, antiga, que as fazia rir e chorar, que elas lembravam e que valia ouro". Registraram essas memórias - não sem certa estranheza e desconfiança - e, posteriormente, montei uma tabela resumindo os episódios e sentimentos destacados por elas. Nessa tabela, que levei para a aula na semana seguinte, era possível visualizar as experiências mais marcantes e alguns sentidos e significados da escola expressos por aquelas lembranças.

Alguns depoimentos podem ser destacados:

Me lembro que tremia muito, fiquei muito emocionada quando convidei minha professora da $1^{\mathrm{a}}$ série para ir à minha $1^{\mathrm{a}}$ comunhão. (algo bem antigo)

Tinha um garoto que estudava comigo na $3^{\mathrm{a}}$ série e contava histórias nojentas porque sabia que eu passava mal só de ouvir. (algo que faz rir) 
Na hora do intervalo, na fila, para comer aquelas deliciosas comidas quentinhas. (algo quente)

Das brincadeiras que fazia nos recreios com meus amigos. (algo que você se lembre)

Do dia em que meus amigos me fizeram uma surpresa no meu aniversário. (algo de que se lembre)

Analisamos juntas que a escola havia sido vivida como espaço de encontro com os amigos, onde as confraternizações, festas, formaturas tinham destaque especial. As lembranças das amizades e brincadeiras, como também a merenda na hora do lanche, significavam recordações valiosas. A primeira professora, o carinho de alguns professores, as saudades dos colegas e algumas broncas e peraltices também foram lembradas. Concluímos que a escola tinha o sentido e o valor do encontro, da amizade, das cumplicidades e das diferenças também..

A poesia de Paulo Freire ${ }^{1}$ reflete parte da experiência de escola valorizada e retida na lembrança pelas alunas:

A escola

Escola é...

o lugar onde se faz amigos,

não se trata só de prédios, salas, quadros, programas, horários, conceitos..

Escola é, sobretudo, gente, gente que trabalha, que estuda, que se alegra, se conhece, se estima.

$O$ diretor é gente,

o coordenador é gente, o professor é gente,

o aluno é gente,

cada funcionário é gente.

E a escola será cada vez melhor na medida que cada um se comporte como colega, amigo, irmão.

Nada de "ilha cercada de gente por todos os lados".

Nada de conviver com as pessoas e depois descobrir

Que não tem amizade a ninguém, nada de ser como o tijolo que forma a parede, indiferente, frio, só.

Importante na escola não é só estudar, não é só trabalhar,

é também criar laços de amizade,

é criar ambiente de camaradagem,

é conviver, é se "amarrar nela"!

${ }^{1}$ Poesia disponível no site do Instituto Paulo Freire < http://www.paulofreire.org >.

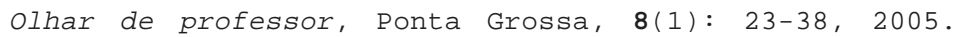


Ora, é lógico...

que numa escola assim vai ser fácil

estudar, trabalhar, crescer,

fazer amigos, educar-se,

serfeliz.

A escola, como diz Paulo Freire, é encontro de gente para cultivar a amizade, a alegria, a camaradagem. Mas também é encontro de gente para estudar, fazer descobertas, produzir conhecimento, fazer planos, tecer projetos. É lugar de formação.

Tomo o sentido de formação, na concepção de Larrosa (2001), que não a resume à questão de aprender algo, uma relação exterior entre sujeito e aquilo que se aprende, mas a considera uma experiência em que alguém, no início, era de uma maneira e, ao final, converteu-se em outra coisa.

A formação, nessa perspectiva, é entendida como uma relação interior com a matéria de estudo na qual o aprender forma ou transforma o sujeito, isto é, o sujeito se volta para si mesmo, é levado para si mesmo, vai sendo levado à sua própria forma. Assim, como espaço de formação e transformação do sujeito, a escola precisa "marcar" cada aluno com a perspectiva do conhecimento, do estudo, da aprendizagem, da superação.

As memórias construídas a partir da provocação do livro de literatura infantil foram pouco relacionadas ao conhecimento e ao estudo. Das 15 alunas que realizaram a atividade de re- gistro das lembranças da escola, no início do curso, somente 5 fizeram esse tipo de referência.

Todos os meus livros e principalmente os professores que podiam tirar nossas dúvidas. (algo que vale ouro)

Os livros que a professora leu. (algo antigo)

$\mathrm{O}$ conhecimento que adquiri e as amizades que fiz. (algo que vale ouro)

Minha aprendizagem. (algo que vale ouro)

No meu primeiro dia de aula, fui convidada para ir até a lousa relembrar os colegas de classe sobre a matéria que fui péssima no ano anterior. Paguei mico, mas valeu a pena relembrar o que passou, uma experiência a mais. (algo de que você se lembre)

Esse dado - lembranças do espaço de encontro, ausência da lembrança do estudo - passou a ser visto como preocupante. Isso porque entendo que para ser professora não basta somente gostar de criança e se identificar com a profissão. Para ser professora é preciso gostar da escola, gostar de estudar, entender que o conhecimento é importante para o nosso desenvolvimento pessoal, intelectual, artístico, estético, ético. É preciso estar identificada com o processo de aprender e sentir prazer em aprender. Como posso assumir o desafio de ensinar e contagiar meus alu- 
nos, se não tenho uma relação prazerosa com o conhecimento, com a leitura, com a escrita, com a necessidade de se encantar com o que não se sabe? Se não me surpreendo com minhas transformações internas, voltome para mim mesma e desenho uma forma?

A partir disso, passei a observar o comportamento das alunas e sua dedicação às leituras, produção de textos, participação, interesse, freqüência, etc. Mesmo sinalizando simpatia pelas aulas e bom relacionamento comigo, o compromisso com as leituras e os trabalhos - com o conhecimento - ficava sempre abaixo das minhas expectativas. As alunas cumpriam o protocolo de entregar os trabalhos e, na maioria das vezes, reclamavam da complexidade ou dificuldade do vocabulário ou, mesmo, da proposta de atividade e reflexão. Não posso desconsiderar que minhas alunas trabalham todo o dia e vão à faculdade à noite, depois de um dia cansativo e exigente. Vão e demonstram prazer pelo encontro e pelas trocas entre os colegas, como na escola básica, parecendo atribuir pouca importância ao estudo e mobilizando pouco esforço para aprender.

Sobrinho (2004) me adverte e recomenda superar a idéia do aluno como sujeito do iluminismo: racional, centrado e obediente às normas e re- gras pedagógicas. É ele quem defende o aluno como "sujeito da educação" e chama a atenção para a pesquisa de Bittencourt (1998), que reconhece que a escola conta com um novo perfil de público escolar que acompanha avanços tecnológicos e um processo de produção e de comunicação sob forte influência do consumismo. A sociedade de consumo transforma o próprio saber escolar em mercadoria.

Mesmo diante desse contexto, ainda tento acreditar que a escola pode estimular a produção de conhecimento e o prazer de conhecer e aprender.

\section{UM SEGUNDO MOMENTO PARA EVOCARLEMBRANÇAS}

No segundo semestre, a classe ganhou novas alunas em decorrência de uma parceria da faculdade com duas prefeituras de cidades vizinhas. As professoras ${ }^{2}$ (que eu esperava no início do ano) estavam chegando à minha classe, a maioria com curso de Magistério, atuando em classes de Educação Infantil e $1^{\text {a }}$. a $4^{\text {a }}$. séries, na expectativa de completar sua formação e atender às exigências de qualificação.

As aulas tornaram-se mais interessantes com a participação e contribuição desse grupo, que trazia dúvidas,

\footnotetext{
${ }^{2}$ A flexão no feminino justifica-se pelo critério de maioria de gênero. A classe contava, contudo, com dois professores.
} 
exemplos, contra-exemplos, enfim, a prática da sala de aula. Contudo, a preocupação com o que a escola significava para o grupo como um todo persistia. Resolvi ir além na minha investigação.

Assumi meu trabalho como pesquisa, qualificando-me como professora-pesquisadora. A discussão sobre a professora-pesquisadora pode ser encontrada em Geraldi, Fiorentini e Pereira (2000), e Esteban e Zaccur (2002).

Em trabalho publicado recentemente (CUNHA e PRADO, 2004), entendemos que a professora-pesquisadora é aquela que busca razões para conhecer, ou seja, que interroga a própria prática, centrada na análise de seu saber-fazer, socializando sua produção.

Fiorentini (2004, p. 249) entende que a pesquisa do professor é validada na medida em que for um

trabalho intencional, planejado e constituído em torno de um foco ou questão de sua prática; for metódico (passe por algum processo de produção/organização e análise escrita de informações) e resulte num produto final (texto escrito ou relato oral) que traga novas compreensões sobre a prática.

Com essas características de trabalho, propus duas questões dirigidas às alunas:

- De suas memórias de escola, narre/descreva um episódio marcante e significativo que tenha ocorrido no espaço da escola.

- Narre/descreva uma experiência significativa ocorrida na escola e que se relacione com o conhecimento, com o estudo, ou seja, com a aprendizagem.

A primeira questão foi planejada para a memória passear mais livremente, envolvendo qualquer lembrança da escola. Meu objetivo era analisar quantas alunas iriam se referir à escola nesse primeiro momento, ou seja, quantas alunas espontaneamente associariam a escola como espaço de transmissão, socialização ou construção de conhecimento. A segunda questão, entregue somente depois de respondida a primeira pergunta, dirigia a memória para a relação conhecimento-estudo-aprendizagem e eu poderia observar as experiências mais significativas nesse campo.

Apresento alguns registros referentes à primeira questão - De suas memórias de escola, narre/descreva um episódio marcante e significativo que tenha ocorrido no espaço da escola:

Lembro-me das minhas amizades, algumas pessoas que começaram comigo no $1^{\circ}$. ano escolar e estudamos todas as séries até o $3^{\circ}$. colegial. Guardo boas lembranças de alguns professores que também acompanharam minha infância e adolescência. Tenho muita saudade de quando criança, de gincanas e competições, 
adorava dançar e ganhava quase todas as competições.

Da minha infância e adolescência eu sempre fui tímida, quieta. Tinha colegas com quem eu nem conversava, era só "Oi" e mais nada. Chegava na escola, sentava no meu lugar de sempre e nem abria a boca. Até o dia em que a professora resolveu pegar no meu pé para eu ler em voz alta. Nunca gostei porque eu fico vermelha, começo a gaguejar. Mas toda vez que essa professora me chamava, meu rosto queimava, parecia estar pegando fogo. Meus colegas riam de mim sempre e eu não gostava, mas acabei acostumando.

Um dos fatos marcantes de que me lembro é quando eu estava na $3^{a}$. série e minha professora dava um presente para o aluno no dia do seu aniversário. Era apenas uma lembrancinha, mas que todo mundo gostava. Como faço aniversário nas férias, eu imaginava que não iria ganhar presente. Então, resolvi um dia chegar na escola e dizer que era meu aniversário. Todos cantaram parabéns e ganhei uma caixinha de lápis de cor. Mas fiquei morrendo de medo da professora dizer a verdade para todos, pois acho que ela sabia, mas não disse a verdade.

As respostas das 46 alunas para essa primeira questão estão agora agrupadas para melhor compreensão e análise. Muitas delas fizeram mais de uma referência aos episódios escolares, dentre os quais alguns merecem destaque:

20 referências a atividades na escola: formatura (4); brincadeiras (4); viagens (3); teatro (2); festas (2); gincanas; exposições de trabalho para a classe; atividades na quadra.

- 12 referências a sentimentos e relacionamentos: timidez (2); amizades; rejeição dos amigos; dificuldades com os colegas; amor de infância; decepção com a paquera; frustração por não ter o brinquedo da moda; decepção com perda de jogo; preocupação com a doença de um professor; exclusão; ida à escola no colo da mãe.

11 referências a características ou vínculo com o/a professor/a: festa para a professora (2); professora brava (2); ser querida ou receber atenção (3); implicância da professora; professores "curiosos e diferentes"; preconceito racial contra a professora; mentira para ganhar um presente da professora.

- 8 referências ao aprendizado: aprender a ler e escrever; medo dos exames; sala agrupada; divisão da classe em grupos forte, médio e fraco; deslumbre com a Filosofia; jogos e brincadeiras de Matemática; planos de aula e estágios do Magistério.

Outras referências: bagunça (2); "cola"; bomba; fogo na cortina; merenda.

Diante da primeira questão, sem

Olhar de professor, Ponta Grossa, 8(1): 23-38, 2005. 
dirigir a atenção das alunas às questões relativas ao estudo e aprendizado, a escola foi lembrada, principalmente, como lugar de atividades e relacionamentos.

As memórias recordam momentos de interação entre alunos nos contextos de festas, formaturas, competições, exposições, brincadeiras. A escola é pensada como espaço do encontro e das comemorações. Muitos sentimentos são mobilizados nesses encontros: amizades e algumas decepções com colegas, sentimentos de pertencimento e rejeição, frustrações e alegrias, perdas e ganhos.

Lembrar da escola também permitiu que muitos alunos recuperassem as impressões e expectativas em relação aos professores. As lembranças positivas e o carinho dirigido aos professores e recebido pelos alunos, nesse momento, superam as queixas ou críticas.

A referência à escola como espaço de formação, entretanto, é pequena. Nenhuma observação sobre aulas importantes, leituras interessantes, trabalhos marcantes, facilidades, dificuldades, superações. O encanto de aprender a ler e a escrever e o "deslumbre" com a filosofia foram as duas únicas referências nesse sentido. As outras observações relacionam-se à organização e ao encaminhamento do trabalho pedagógico - divisão da sala, classificação de alunos, exames e a experiência de produção de planos de aula e estágio no curso do Magistério.
A segunda questão - Narre/descreva uma experiência significativa ocorrida na escola e que se relacione com o conhecimento, com o estudo, ou seja, com a aprendizagem - é ilustrada com alguns depoimentos:

Vou falar da pior experiência que passei na fase escolar. Vou começar dizendo que fui uma aluna regular para ruim no primário todo, até que na $6^{a}$. série reprovei. Foi uma experiência muito chata e vergonhosa, mas consegui superar. Não me envolvia com os alunos e me fazia de invisivel para os professores para, que eles não se lembrassem de mim (...). Só fui acordar para a importância do estudo na $8^{a}$. série, quando consegui espantar a todos. Acho que foi o meu momento.

Lembro que na $8^{a}$. série fizemos uma Feira de Ciências, ficamos semanas e semanas discutindo quem iria participar. Acabei ficando com a parte de explicar o olho. Fiquei muito empolgada e com medo, pois era uma responsabilidade muito grande "explicar o olho para muita gente”. Me esforcei, fui atrás, estudei muito e consegui. Consegui até um olho de vaca para poder explicar as partes do olho. No final da Feira de Ciências tiramos nota 10, não só pelo trabalho exposto e sim também pela dedicação e esforço pelo trabalho. 
A matéria com a qual eu mais me identifiquei foi Química. No $3^{\circ}$. ano do Ensino Médio, tive um ótimo professor que explicava e fazia com que eu entendesse e me interessasse pelo assunto. Como eu e outros alunos nos interessávamos muito, formamos um grupo em horário e período diferente das aulas para podermos fazer experiências e aprofundar mais o assunto. Eu descobri que a Química não é complicada, mas sim interessante e fascinante.

Analisando as referências à escola, depois do direcionamento, podemos organizá-las da seguinte maneira:

- Vinte e cinco referências a atividades de aprendizagem na escola: exposição de trabalhos para os colegas de classe (5); trabalhos em grupo (3); visitas ao laboratório de Ciências (3); temas específicos (3); pesquisa de campo (2); palestras (2); ensaiar e cantar; maquete; concurso de Literatura; exposição de trabalhos; jogos e brincadeiras de Matemática; ser alfabetizada; debates; atividades de reciclagem; atividades de Artes; Feira de Ciências; curso do PROFA; estágios do Magistério.

- Onze referências a características ou vínculo com o/a professor/a: apoio e carinho da professora (6); ser deixada de lado; bom professor; professor ruim; professor exigente; identificação com a professora.

- Doze referências a sentimentos e relacionamentos: humilhação (2); vergonha da reprovação (2); medo das crianças; frustração pela nota baixa; sentir-se capaz; vigiar os amigos; dificuldade em aprender; raiva/ prazer de ler; prazer de ajudar colegas; ser "pesquisadora"; identificação com crianças nos estágios do Magistério.

Reconhecendo, mais uma vez, que a escola foi vivida como espaço de encontro e interação, a maioria das referências à aprendizagem está situada no contexto de trabalhos em grupo, exposições para a classe, pesquisas de campo. As visitas ao Laboratório, bem como as palestras, Feira de Ciências, atividades com artes e reciclagem, ensaios, jogos e brincadeiras também dão o sentido do coletivo, do agrupamento, do estar junto.

Os sentimentos e relacionamentos experimentados na vida escolar são os mais diversos e mobilizam narrativas que expressam a intensidade das lembranças.

Pensar a relação com o conhecimento também implicou lembrar dos professores. Nesse caso, tanto o sentimento de ser acolhida - experiência predominante - quanto discriminada, rejeitada e avaliada repercutiram nas memórias das alunas. O olhar da professora - de admiração ou crítica - é significativo em várias lembranças.

É fato, como indica Arroyo (2000), que a matriz de nossa formação é a interação com outros, uma vez que o conhecimento, os valores e as competências se aprendem no intercâmbio humano. A questão que se colo- 
ca para reflexão é que nenhuma aluna se lembra de horas de estudo, de lições, leituras, temas, produções de texto, do intercâmbio de aprendizagem, do diálogo com professores e autores. Não existem referências à dedicação, investimento de tempo, disciplina, sentimento de responsabilidade para com a escola. Nenhuma reflexão sobre voltar-se para si mesmo, encontrar sua própria forma, sua maneira própria (LARROSA, 2001).

\section{A ESCOLA: ESPAÇO DE SOCIA- LIZAÇÃO E FORMAÇÃO?}

Esses dados revelaram que as escolas de ensino fundamental e médio não contribuíram para a valorização do conhecimento e não se constituíram como espaços significativos de socialização e construção de conhecimento. A experiência enquanto alunas foi marcada pelo encontro com pessoas, com sentimentos de amizade, conflitos e relações intensas com colegas e professores. A escola fica, assim, caracterizada como espaço de encontros e sentimentos.

É Arroyo (2001) quem registra que, além dos conhecimentos que ensinamos, as posturas, processos e significados postos em ação na escola, bem como os hábitos, é que influenciam nossos pensamentos, raciocínio, nossos gestos, sensibilidades, formas de fazer, compartilhar, intervir. São esses conhecimentos e hábitos interna-lizados pelos professores na sua experiência escolar, traduzidos nas memórias registradas, que nos permitem interrogar se o vínculo com o processo de aprender está bem estruturado de forma a apoiar a experiência de ensinar.

A educação, na perspectiva da formação social, implica posturas e relacionamentos que permitam a expressão da liberdade, da autenticidade e da responsabilidade (GALLO, 2000), mas também implica a instrumentalização de conteúdos.

O problema que se coloca é que a experiência da maioria das alunas com os conteúdos escolares não provocou encanto e prazer. Isso talvez possa ser justificado, recorrendo a Gallo (2000), pela compartimentalização do trabalho pedagógico. A realidade do ensino é a compartimentalização do saber, decorrente da especialização do saber. A escola organiza esse saber através das disciplinas. Com a fragmentação do conhecimento, os alunos não conseguem perceber que todos os conhecimentos vivenciados na escola são perspectivas diferentes de uma mesma e única realidade e que a realidade só pode ser compreendida na totalidade.

Morin (2000) e Alves e Garcia (2000) concordam que a disciplinaridade ofereceu grande contribuição ao desenvolvimento da ciência, permitindo o aprofundamento e a ampliação das diferentes áreas do conhecimento. Entretanto, consideram que essa fragmentação comprometeu o entendimento dos seres humanos, da natureza e da sociedade. 
Alves e Garcia (2000) apontam a organização da escola nessa realidade e questionam os critérios de seleção dos conteúdos pedagógicos, a ênfase na "normalização de seqüências", a hierarquização dos conteúdos, com espaços/tempos maiores para alguns em detrimento de outros, além da homogeneização do conhecimento oficial, que "nega" os saberes velados. Argumentam que o currículo construído desse modo fragmentado precisa ser revisado com vistas a um diálogo transdisciplinar, de modo que os conhecimentos sejam religados para ganharem sentido.

O desinteresse dos alunos é justificado por Cortella (1999) como decorrência do distanciamento entre os conteúdos programáticos e as preocupações que os alunos trazem para a escola, isto é, entre os conteúdos escolares e o universo vivencial dos alunos. O autor aponta ainda a importância da ludicidade para a infância e para a adolescência, assim como a amorosidade. Para ele, a sala de aula é lugar de relações afetivas e impõe dedicação, confiança mútua, maleabilidade e prazer compartilhado.

Relações afetivas, confrontos, conflitos, paixões, medos e adesões apareceram com freqüência nas memórias das futuras professoras. Mas, e o prazer compartilhado?

Assim, a criação e a recriação do Conhecimento na escola não está apenas em falar sobre coisas prazerosas, mas, principalmente, em falar prazerosamente sobre as coisas; ou seja, quando o educador exala gosto pelo que está ensinando, ele interessa nisso também o aluno. Não necessariamente o aluno vai apaixonar-se por aquilo, mas aprender o gosto é parte fundamental para passar a gostar. (CORTELLA, 1999, p. 124).

$\mathrm{O}$ encantamento recíproco entre conhecimentos, preocupações e interesses dos alunos precisa ser mediado pelo professor. Os alunos, para voltarem-se para si e ao mesmo tempo voltarem-se para o outro, estabelecendo uma comunicação solidária, dependem do professor.

Faz-se necessário ressaltar, contudo, que a responsabilidade pela formação dos alunos e os resultados do ensino não são exclusivos do professor, excessivamente responsabilizado pelas mazelas da educação. Franchi (1995) destaca que existe um mal estar profissional dos professores, que vivem tempos difíceis e paradoxais. Sua competência profissional é constantemente alvo de críticas e deles se exige quase tudo. O declínio social e ético é alimentado pelas condições de trabalho, degradação dos salários, inadequação de critérios de ascensão na carreira, acúmulo de aulas, que se refletem muitas vezes na falta de estímulo, interesse, falta de crítica, acomodação. 


\section{CONSIDERAÇÕES FINAIS}

Recuperar e registrar as memórias são estratégias interessantes na formação de professores/as pela possibilidade que inauguram de dar sentido à própria trajetória e projetar uma direção ao que ainda se pretende construir e experimentar (CUNHA, 2004). Nos fragmentos das memórias das futuras professoras cada uma se exprime, transformando-se num objeto de conhecimento para o outro e para si mesma, denunciando como ela se reconhece, suas maneiras de sentir, aprender e se relacionar com os outros e com o mundo. Conhecendo as memórias das alunas, é possível propor situações que estimulem a reflexão sobre o percurso escolar, ressignificando as experiências com a escrita, leitura, estudo, avaliação, aprendizagem, compromisso.

Pensar sobre a realidade e sobre as memórias das alunas dos cursos de formação inicial de professores é fundamental para que ajustemos as expectativas e desfaçamos algumas idealizações. É uma alternativa para aproximarmos nossos programas de ensino às preocupações e universos vivenciais das futuras professoras. Do contrário, seremos parte da engrenagem que focaliza as disciplinas e seqüências didáticas, e que negligencia a alegria de compartilhar o saber.

É preciso que os cursos de formação inicial de professores criem uma atmosfera que valorize o processo de conhecer, de estudar, o compromisso de investigar e superar as próprias limitações e, acima de tudo, desencadear um prazer necessário ao ofício de ensinar. Uma formação inicial que não reproduza a mesma experiência da escola básica.

Os professores e a instituição devem chamar para si o enorme desafio de construir uma escola coerente com o propósito de formar professores: compromissada e ética nos seus relacionamentos e encaminhamentos.

\section{REFERÊNCIAS}

ALVES, N.; GARCIA, R. L. Para começo de conversa. In: O sentido da escola. Rio de Janeiro: DP\&A, 2000. p. 7-16.

ANDRÉ, M. E. Prática docente e cotidiano escolar. Relatório de Pesquisa. FEUSP, 1993.

ARROYO, M. G. Ofício de mestre: imagens e auto-imagens. Petrópolis: Vozes, 2000.

BITTENCOURT, C. (Org.). O saber histórico em sala de aula. São Paulo: Contexto, 1998.

CORTELLA, M. S. A escola e o conhecimento: fundamentos epistemológicos e políticos. São Paulo, Cortez: Instituto Paulo Freire, 1999.

CUNHA, M. I. Aula universitária: inovação e pesquisa. In: LEITE, D.; MOROSINI, M. (Orgs.). Universidade futurante: produção do ensino e inovação. Campinas: Papirus, 1997. 
A docência como ação complexa: o papel da didática na formação de professores. In: ROMANOWSKI, J. P.; MARTINS, P. L. O.; JUNQUEIRA, S. R. (Orgs.). Conhecimento local e conhecimento universal: pesquisa, didática e ação docente. Curitiba: Champagnat, 2004.

O bom professor e sua prática. Campinas: Papirus, 1988.

CUNHA, R. B. As memórias nos clássicos e nossas clássicas memórias. 2004. (mimeo)

; PRADO, G. V. T. A professorapesquisadora e o professor-pesquisador na escola: estudar, pensar, saber. In: XII ENDIPE - CONHECIMENTO LOCAL E CONHECIMENTO UNIVERSAL. Anais..., Curitiba, 2004.

ESTEBAN, M. T.; ZACCUR, E. (Orgs.). Professora-pesquisadora: uma práxis em construção. Rio de Janeiro: DP\&A, 2002.

FIORENTINI, D. A didática e a prática de ensino mediadas pela investigação sobre a prática. In: ROMANOWSKI, J. P.; MARTINS, P. L. O.; JUNQUEIRA, S. R. (Orgs.) Conhecimento local e conhecimento universal: pesquisa, didática $\mathrm{e}$ ação docente. Curitiba: Champagnat, 2004.

FOZ, M. Guilherme Augusto Araújo Fernandes. São Paulo: Brinque-Book, 1995.

FRANCHI, E. P. (Org.). A causa dos professores. Campinas: Papirus, 1995.

GALLO, S. Transversalidade e educação: pensando uma educação não-disciplinar. In: ALVES, N.; GARCIA, R. L. O sentido da escola. Rio de Janeiro: DP\&A, 2000.

GARCIA, R. L.; ALVES, N. Conversa sobre pesquisa. In: ESTEBAN, M. T.; ZACCUR, E (Orgs.). Professora-pesquisadora: uma práxis em construção. Rio de Janeiro: DP\&A, 2002.

GERALDI, C. M. G.; FIORENTINI, D.; PEREIRA, E. M. A. (Orgs.). Cartografias do trabalho docente: professor(a)pesquisador(a). Campinas: Mercado de Letras, 2000.

MORIN, E. Articular os saberes. In: ALVES, N.; GARCIA, R. L. O sentido da escola. Rio de Janeiro: DP\&A, 2000.

PIMENTA, S. G. Professor reflexivo: construindo uma crítica. In: PIMENTA, S. G.; GHEDIN, E. (Orgs.). Professor reflexivo no Brasil: gênese e crítica de um conceito. São Paulo: Cortez, 2002.

PIMENTEL, M. G. O professor em construção. Campinas: Papirus, 1993.

PORTO, Y. S. Formação continuada: a prática pedagógica recorrente. In: MARIN, A. J. (Org.). Educação continuada: reflexões e alternativas. Campinas: Papirus, 2000.

SACRISTÁN, J. G.; PÉREZ GÓMEZ, A. I. Compreender e transformar o ensino. Porto Alegre: ArtMed, 1998.

SOBRINHO, A. F. O aluno não é mais aquele! E agora professor?: O ensino de história e os sujeitos do cotidiano na contemporaneidade. In: ROMANOWSKI, J. P.; MARTINS, P. L. O.; JUNQUEIRA, S. R. (Orgs.). Conhecimento local e conhecimento universal: pesquisa, didática e ação docente. 4 . ed. Curitiba: Champagnat, 2004.

SANTOS, J. M. T. P. O limite da necessidade: as condicionalidades interpostas à realização do trabalho educativo na escola. In: FERREIRA, N. S. C. Supervisão educacional para uma escola de quali- 
dade: da formação à ação. São Paulo:

Cortez, 2002.

Encaminhado em 10/12/04

Aceito em 16/05/05 